\title{
Michael reactions carried out using a bench-top flow system
}

\author{
Frederic Bonfils, ${ }^{a}$ Isabelle Cazaux, ${ }^{a}$ Philip Hodge ${ }^{* a}$ and Claude Caze ${ }^{b}$
}

\author{
Received 26th October 2005, Accepted 23rd November 2005 \\ First published as an Advance Article on the web 15th December 2005 \\ DOI: $10.1039 / b 515241 k$
}

The Michael reaction between methyl 1-oxoindan-2-carboxylate and methyl vinyl ketone was achieved successfully by pumping solutions of the reactants in toluene through a fluid bed of Amberlyst A21 at $50{ }^{\circ} \mathrm{C}$. The use of a fluid bed reactor is attractive as it allows gel-type beads, i.e. the type of bead used in most studies of polymer-supported (PS) organic reactions, to be used satisfactorily in a flow system. When polymer-supported cinchonidine was used in place of Amberlyst A21, the Michael product was obtained in high yield with an enantiomeric excess (ee) of $51 \%$. This $\%$ ee is comparable to that achieved when the reaction was catalysed by cinchonidine itself.

\section{Introduction}

Polymer-supported (PS) organic reactions, i.e. reactions where at least one of the reactants is attached to a polymer, have been of great interest in recent years because the use of a polymer support greatly simplifies the isolation of the desired product. ${ }^{1,2}$ In some instances reaction systems have been automated., ${ }^{3,4}$ PS reagents and catalysts are of particular interest because the organic substrates and the desired products are in solution and, as a consequence, reactions using them are easily monitored by traditional methods such as thin layer chromatography and ${ }^{1} \mathrm{H}$ NMR spectroscopy. ${ }^{1,2,5}$ There is now interest in developing PS reagents and catalysts further and using them in bench-top flow systems. Progress in this area has been reviewed recently. ${ }^{6-12}$ This article describes some Michael reactions carried out in a benchtop flow system. Whilst anion exchange resins have previously been used in the batch mode to catalyse Michael reactions, ${ }^{13}$ this appears to be the first time such a Michael reaction has been studied in a flow system.

Flow systems have several advantages over batch reactions. ${ }^{6-8}$ For example, (i) the PS reactants suffer less physical damage than in a stirred reaction; (ii) often they allow reactions to be carried out with little or no work up; (iii) they allow reaction conditions to be reproduced relatively easily; (iv) flow systems have the potential for easy automation including feedback on the progress of the reaction; (v) they have the potential to be adapted for the continuous production of product and an easier scale-up from laboratory to plant; and (vi) they have the potential to allow reactions to be carried out in a greener manner.

\section{Results and discussion}

This article is concerned with carrying out Michael reactions between methyl 1-oxoindan-2-carboxylate (1) and methyl vinyl ketone (2) to give adduct 3 [Reaction (1)] in a flow system. This well-known reaction was chosen as a model for the present study

${ }^{a}$ Department of Chemistry, University of Manchester, Oxford Road, Manchester, UK M139PL. E-mail: Philip.Hodge@man.ac.uk; Fax: +44 (0)1524 793 252; Tel: +44 (0) 1612754707

${ }^{b}$ Laboratoire de Chimie Macromoleculaire URA CNRS 351, Universite des Sciences et Technolgies de Lille, 59685 Cedex, Villeneuve d'Ascq, France because it is catalysed by tertiary amines and it has the possibility to be adapted for asymmetric synthesis. The reaction was studied in considerable detail by Wynberg et al. ${ }^{14,15}$ They showed that this indanone derivative is more reactive than some closely related cyclohexanone derivatives and they studied asymmetric syntheses using cinchona alkaloids as catalysts. ${ }^{14}$ Other research groups have since studied the reaction using cinchona alkaloids or derivatives. ${ }^{16-23}$ A wide variety of other compounds ${ }^{24}$ have also been used as catalysts.

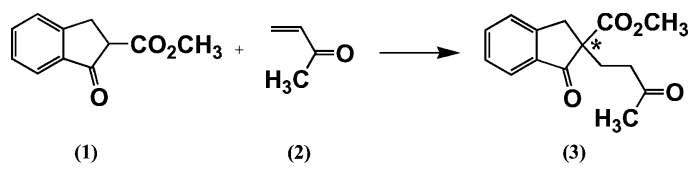

\section{Flow apparatus}

In the present study Reactions (1) were achieved by passing solutions of reactants $\mathbf{1}$ and $\mathbf{2}$ through a column of a PS tertiary amine. The type of flow system used had a fluid bed of beads. This is attractive for using with gel-type beads, or other types that swell in the reaction solvent, as it allows for the bed volume to change easily and it avoids the clogging that could occur with soft beads in a fixed bed reactor, especially if pressure were to be applied. As the beads can move round in the fluid bed, individual beads do not permanently reside in a part of the reactor where flows may be poor, and so all the beads have an equal opportunity to play a part in the catalysis.

The flow apparatus, which is similar to one used previously, ${ }^{25}$ is shown schematically in Fig. 1. It consists of a glass tube $36 \mathrm{~cm}$ long and $14 \mathrm{~mm}$ wide (volume $55 \mathrm{ml}$ ) with one end closed. The other end is sealed with a septum cap. The PS amine is placed in the tube and the tube immersed in a constant temperature bath to a sufficient depth to cover the column of beads. Using peristaltic pumps solutions of the reactants are pumped, via separate long syringe needles, to the bottom of the tube. The soluble reactants pass up through the fluid bed of beads and the product solution is taken from the top of the bed by a third syringe needle. The placement of this needle allows the liquid level in the column to be controlled easily such that the bed of beads extends from the very bottom of the column up to the take off needle. Thus, under these 


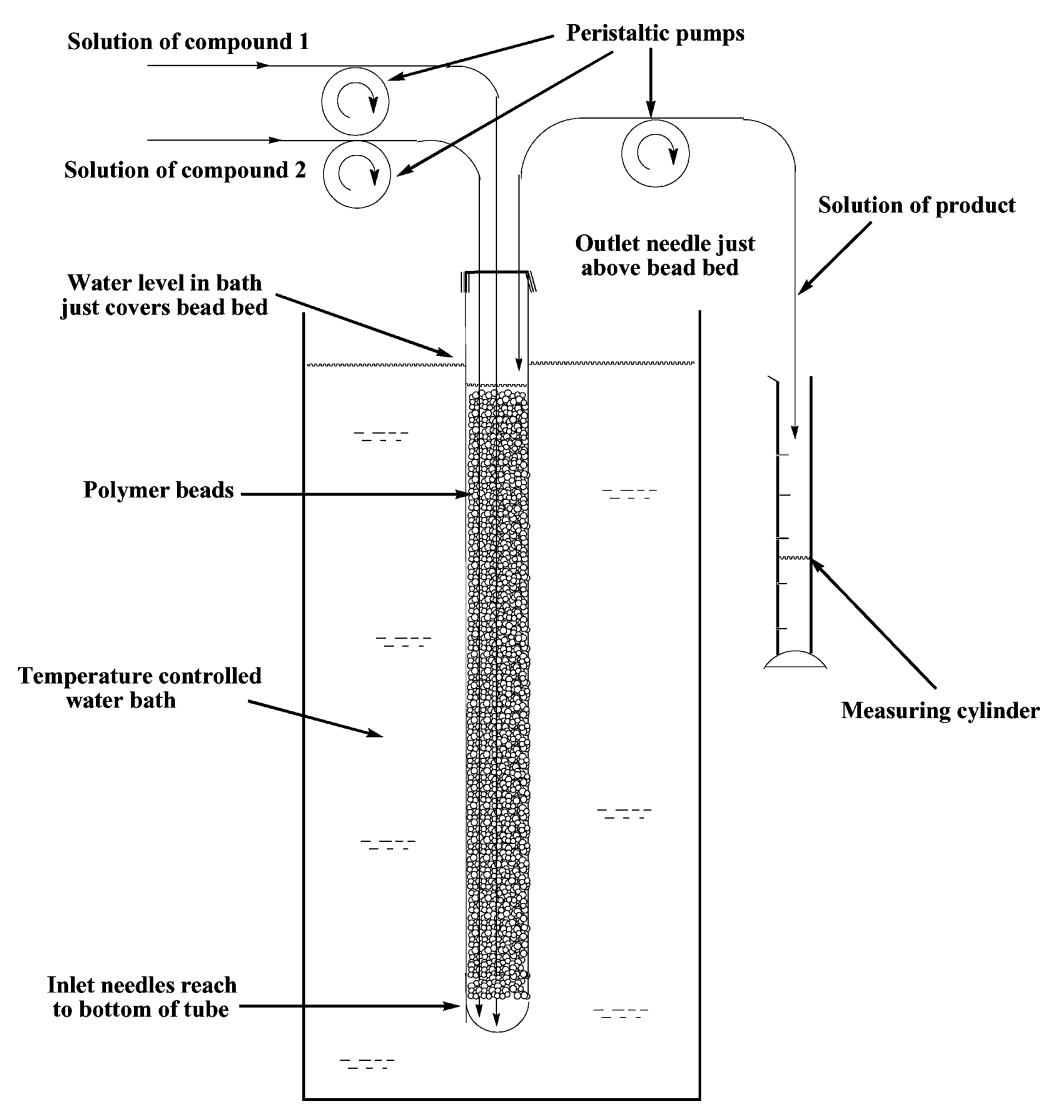

Fig. 1 General arrangement of the flow system.

conditions the volumes of solution above and below the bed are minimized. The eluate was collected as fractions $(10 \mathrm{ml})$. These were evaporated to dryness, dissolved in ether and extracted with aqueous base to remove unreacted compound $\mathbf{1}$. The solution was dried and the ether evaporated. The residue was analysed by thin layer chromatography and by ${ }^{1} \mathrm{H}$ NMR spectroscopy.

\section{Catalysis of Reaction (1) by Amberlyst A21}

Initially, to gain experience of carrying out Michael Reaction (1) in a flow system, reactions were carried out using Amberlyst A21, a commercially available ion exchange resin. This resin contains residues 4 ( $c$ a. $\left.5.00 \mathrm{mmol} \mathrm{g}^{-1}\right)$ and is in the form of $490-690 \mu \mathrm{m}$ diameter macroreticular beads. The flow tube was packed with $15.5 \mathrm{~g}(79 \mathrm{mmol})$ of dried beads. These occupied $42 \mathrm{ml}$. When toluene was added the beads swelled and the bed volume increased to $49 \mathrm{ml}$. Solutions of the $\beta$-ketoester 1 in toluene $\left(0.50 \mathrm{mmol} \mathrm{ml}^{-1}\right)$ and methyl vinyl ketone (2) in toluene $\left(0.53 \mathrm{mmol} \mathrm{ml}^{-1}\right)$ were separately pumped at the same rate into the column. The ketone 2 was used in excess because it is volatile and so an excess can be removed easily from the eluate.

Different flow rates and different reaction temperatures were used to optimize the conversion to compound 3: see Table 1. Throughout the volume of the bed was essentially constant at $49 \mathrm{ml}$. Initially reactions were carried out at $20{ }^{\circ} \mathrm{C}$ but it is evident (see Table 1 entries 1 and 2 ) that the reaction is very slow at this temperature with a residence time (i.e. [volume of solution in the bead bed] divided by [the flow rate]) of $>24 \mathrm{~h}$ required to obtain significant yields of compound $\mathbf{3}$. This was considered to be unsatisfactory for a flow system so the reaction temperature was raised to $50{ }^{\circ} \mathrm{C}$ and further reactions were carried out: see entries 3-6. At a flow rate of $7.0 \mathrm{ml} \mathrm{h}^{-1}$, corresponding to a residence time of $c a$. $6 \mathrm{~h}$, very high yields of 3 were obtained: see entry 5 . The column was then used continuously under these conditions for $72 \mathrm{~h}$ without any drop in the yield of 3 ; see entry 6 . Approximately $10 \mathrm{~g}$ of compound 3 could be produced in $24 \mathrm{~h}$.<smiles>CNCc1ccc(C(CC(C)C)C(C)(C)C)cc1</smiles>

(4)

\section{Catalysis of Reaction (1) by cinchona alkaloids}

Since compound 3 contains a chiral centre, asymmetric synthesis can potentially be achieved by using a chiral tertiary amine as the catalyst. Cinchona alkaloids have been used for this purpose. ${ }^{14,19}$ Quinine (5) and cinchonidine (6) give an excess of the (-)- $(S)$ enantiomer whilst quinidine (7) and cinchonine (8) give an excess of the $(+)-(R)$-enantiomer. ${ }^{14,19}$ In the present work batch reactions were carried out by treating mixtures of compounds $\mathbf{1}$ and $\mathbf{2}$ in toluene with $5 \mathrm{~mol} \%$ of cinchonidine (6) and with $5 \mathrm{~mol} \%$ of cinchonine $(8)$ at $25{ }^{\circ} \mathrm{C}$. The results are summarized in Table 2, entries 1 and 2 . It is evident that the reactions are very slow at this temperature and that cinchonidine (6) affords the higher \% ee. In 
Table 1 Synthesis of compound 3 using the flow system shown in Fig. $1^{a}$

\begin{tabular}{|c|c|c|c|c|c|c|c|c|}
\hline \multirow[b]{2}{*}{ Entry } & \multirow[b]{2}{*}{ Catalyst $^{b}$} & \multicolumn{2}{|c|}{ Reaction conditions } & \multirow[b]{2}{*}{$\begin{array}{l}\text { Approximate } \\
\text { residence time } / \mathrm{h}^{c}\end{array}$} & \multirow[b]{2}{*}{$\begin{array}{l}\text { Average } \\
\text { yield }^{d, e}(\%)\end{array}$} & \multirow[b]{2}{*}{$\begin{array}{l}\text { Duration of } \\
\text { experiment } / \mathrm{h}\end{array}$} & \multirow[b]{2}{*}{$\% \mathrm{ee}^{e, f}$} & \multirow[b]{2}{*}{$\begin{array}{l}\text { Enantiomer } \\
\text { in excess }\end{array}$} \\
\hline & & Temperature $/{ }^{\circ} \mathrm{C}$ & $\begin{array}{l}\text { Total flow } \\
\text { rate } / \mathrm{ml} \mathrm{h}^{-1}\end{array}$ & & & & & \\
\hline 1 & A21 & 20 & 5.0 & 8 & 14 & 12 & - & - \\
\hline 2 & A21 & 20 & 1.0 & 40 & 55 & 48 & - & - \\
\hline 3 & $\mathrm{~A} 21$ & 50 & 21.0 & 2 & 77 & 18 & - & - \\
\hline 4 & A21 & 50 & 10.5 & 4 & 86 & 18 & - & - \\
\hline 5 & A21 & 50 & 7.0 & 6 & 99 & 24 & - & - \\
\hline 6 & A21 & 50 & 7.0 & 6 & 98 & 72 & - & - \\
\hline 7 & PS-CD & 50 & 7.2 & 4 & 92 & 18 & 52 & $(S)$ \\
\hline 8 & PS-CD & 50 & 5.0 & 6 & 97 & 24 & 51 & $(S)$ \\
\hline 9 & PS-CD & 50 & 5.0 & 6 & 96 & 72 & 52 & $(S)$ \\
\hline
\end{tabular}

${ }^{a}$ Solutions of compound $\mathbf{1}\left(0.5 \mathrm{~mol} \mathrm{~L}^{-1}\right)$ and compound $\mathbf{2}\left(0.53 \mathrm{~mol} \mathrm{~L}^{-1}\right)$ in toluene were pumped at the same rate through the catalyst bed under the indicated conditions. In the reactions using Amberlyst A21 the swollen bead bed (15.5 g of beads) occupied $49 \mathrm{ml}$. In the reactions using PS-CD the swollen bead bed ( $15.0 \mathrm{~g}$ of beads) occupied $41 \mathrm{ml} .{ }^{b} \mathrm{~A} 21=$ Amberlyst A21; PS-CD = polymer-supported cinchonidine. ${ }^{c}$ Volume of solution in the bed divided by the flow rate. In the experiments using Amberlyst A21 the volume of solution in the bed was $42 \mathrm{ml}$. In the experiments using PS-CD the volume of solution in the bed was $28.9 \mathrm{ml} .{ }^{d}$ Yield determined by analysis of ${ }^{1} \mathrm{H}$ NMR spectra of eluate after removal of volatile products. ${ }^{e}$ Figure quoted is the average yield ( $\pm 4 \%$ of the values quoted) for 5 fractions. ${ }^{f}$ Determined by polarimetry.

Table 2 Results of experiments using chiral catalysts in batch reactions to achieve Reaction (1) ${ }^{a}$

\begin{tabular}{|c|c|c|c|c|c|c|}
\hline Entry & Catalyst $^{b}$ & \multicolumn{2}{|c|}{ Reaction conditions } & $\%$ Yield $^{c}$ & $\% \mathrm{ee}^{d}$ & Enantiomer \\
\hline 2 & $\mathrm{C}$ & 25 & 48 & 96 & 47 & $(R)$ \\
\hline 3 & CD & 50 & 3 & 91 & 53 & $(S)$ \\
\hline 4 & $\mathrm{C}$ & 50 & 6 & 87 & 47 & $(R)$ \\
\hline 5 & PS-CD & 50 & 24 & 98 & 47 & $(S)$ \\
\hline
\end{tabular}

${ }^{a}$ Compound $1(2.73 \mathrm{mmol})$ and compound $2(4.23 \mathrm{mmol})$ in toluene $(10 \mathrm{ml})$ were stirred with $5 \mathrm{~mol} \%$ of catalyst under the indicated conditions, ${ }^{b} \mathrm{CD}$ $=$ cinchonidine $; \mathrm{C}=$ cinchonine; PS-CD $=$ polymer-supported cinchonidine, ${ }^{c}$ Determined by ${ }^{1} \mathrm{H}$ NMR spectra of products after removal of volatile products. ${ }^{d}$ Determined by polarimetry.

an attempt to shorten the reaction time the reactions were repeated at $50{ }^{\circ} \mathrm{C}$. In many asymmetric syntheses this would result in very much lower \% ees, but in the present case there were only modest falls, see Table 2 entries 3 and 4, and reaction times for high yields could now be reduced to a few hours. Previous studies indicate that when catalyzed by cinchona alkaloids, the \% ees obtained in Reaction (1) are only moderately sensitive to temperature in the $-21{ }^{\circ} \mathrm{C}$ to $+50{ }^{\circ} \mathrm{C}$ range. ${ }^{14,19}$ The $\%$ ees obtained in the present work are comparable with those obtained previously under slightly different reaction conditions. ${ }^{14,19}$

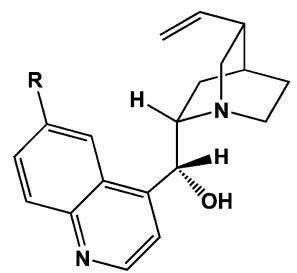

Quinine: (5): $\mathbf{R}=\mathbf{O C H}$ Cinchonidine: (6): $\mathbf{R}=\mathbf{H}$

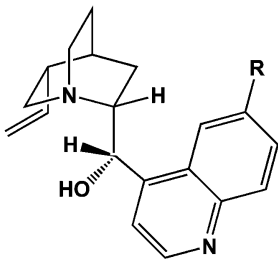

Quinidine: (7): $\mathbf{R}=\mathbf{O C H}_{3}$ Cinchonine: (8): $\mathbf{R}=\mathbf{H}$
Following these preliminary experiments cinchonidine (6) was attached via the vinyl group to gel-type polymer beads using a method first reported by the author: see Reaction (2). ${ }^{26}$ Polystyrene beads ( $1 \%$ crosslinked; $80-150 \mu \mathrm{m}$ in diameter) were chloromethylated ${ }^{27}$ and the product treated with thiourea then aqueous sodium hydroxide to give beads containing thiol groups $9\left(1.76 \mathrm{mmol} \mathrm{g}^{-1}\right) \cdot{ }^{28}$ Reaction of these beads with cinchonidine

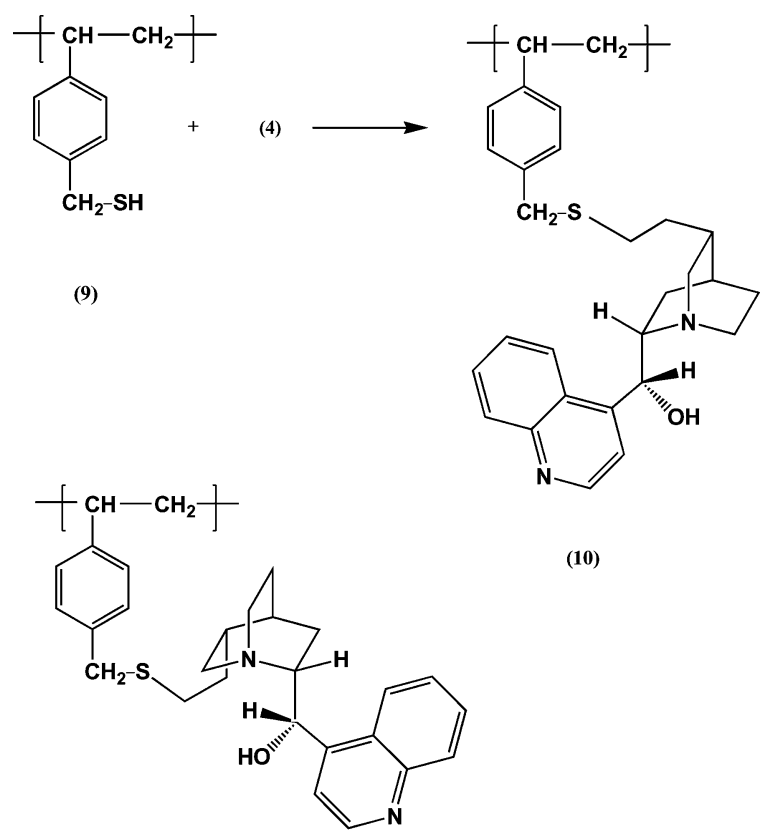

(11) 
(6) in the presence of azobisisobutyronitrile at $60{ }^{\circ} \mathrm{C}$ gave beads with residues 10: unreacted thiol groups were capped by reaction with cyclohex-2-en-3-one. ${ }^{26}$ By elemental analysis for nitrogen the loading of cinchonidine residues $\mathbf{1 0}$ was $0.93 \mathrm{mmol} \mathrm{g}^{-1}$.

The PS cinchonidine $\mathbf{1 0}$ was used in batch reactions to catalyse Reaction (1). The results are summarized in Table 2, entries 5 and 6 . Interestingly the $\%$ ees obtained were only slightly lower than those obtained with the free alkaloid. Initially this was surprising because in the asymmetric addition of thiols to $\alpha, \beta$-enones (another type of Michael addition) the $\%$ ees are substantially lower with the PS cinchonidine catalyst $\mathbf{1 0}$ and cinchonine catalyst $\mathbf{1 1}$ than with the free alkaloids. ${ }^{26}$ With the PS cinchonine catalyst $\mathbf{1 1}$ the difference was shown to be due to the change from vinyl groups to $\mathrm{ArCH}_{2} \mathrm{SCH}_{2} \mathrm{CH}_{2}$ groups rather than any "polymer effect". ${ }^{26}$ It should be noted that in cinchonidine (6) the vinyl and aromatic groups are on opposite sides of the azabicyclcooctane unit, whereas in cinchonine (8) they are on the same side. Also that the arrangement of the reactants in the transition states of the two types of Michael additions may be quite different. ${ }^{21}$

The PS cinchonidine $\mathbf{1 0}$ beads $(15.0 \mathrm{~g}, 14 \mathrm{mmol})$ were placed in the flow tube and reactions were carried out at $50{ }^{\circ} \mathrm{C}$ using the same procedure as with Amberlyst A21. The bed volume was essentially constant at $41 \mathrm{ml}$. The results are summarized in Table 1, entries 7-9. At an optimum flow rate of $5.0 \mathrm{ml} \mathrm{h}^{-1}$, see entry 8 , the chiral product $\mathbf{3}$ was obtained in high yield and an ee of $51 \%$. The residence time was $c a$. $6 \mathrm{~h}$. The flow system functioned satisfactorily for at least $72 \mathrm{~h}$ : see entry 6 . The $\%$ ees obtained using the flow system are essentially the same as those obtained in the batch reactions (Table 2, entries 5 and 6). This has been found to be the case in other asymmetric syntheses, ${ }^{6,8}$ though for the reaction of benzaldehyde with diethylzinc the $\%$ ees were found to be substantially higher in flow systems. ${ }^{25,29}$

\section{Conclusions}

Michael Reaction (1) can be carried out successfully by pumping solutions of compounds $\mathbf{1}$ and $\mathbf{2}$ through the simple flow system outlined in Fig. 1. This uses a fluid bed of beads and is an attractive type of system in that it allows gel-type beads, i.e. the type of bead used in most studies of PS organic reactions, ${ }^{1-3}$ to be used satisfactorily in a flow system. In the present studies under optimum conditions chemical yields were high and, when the PS cinchonidine $\mathbf{1 0}$ was used as the catalyst the \% ees of the $(S)$ enantiomer of adduct 3 were essentially the same as in the batch reactions. Future studies will be aimed at developing PS scavengers to remove the unreacted starting materials. ${ }^{5,30}$

\section{Experimental}

Experimental details are as given previously. ${ }^{25}$ Beads were dried in a vacuum oven (2 Torr) at $40{ }^{\circ} \mathrm{C}$. Cinchonidine (6) and cinchonine (8) were purchased from Aldrich and used as received.

\section{Amberlyst A21}

Commercially supplied beads ( $106.5 \mathrm{~g})$ were washed successively with water $(3 \times 200 \mathrm{ml})$, acetone $(2 \times 100 \mathrm{ml})$, tetrahydrofuran $(2 \times 100 \mathrm{ml})$ and ether $(2 \times 100 \mathrm{ml})$ The beads were then dried to constant weight $(45.4 \mathrm{~g})$. By elemental analysis they contained $7.11 \%$ nitrogen, corresponding to $5.08 \mathrm{mmol} \mathrm{g}^{-1}$ of moieties 4 .

A portion of the beads $(6.60 \mathrm{~g})$ was placed in a measuring cylinder $(100 \mathrm{ml})$. The dry beads occupied $18.0 \mathrm{ml}$. Toluene $(60 \mathrm{ml})$ was added and the beads allowed to swell and settle over 2 days. The bed of beads then occupied $21.0 \mathrm{ml}$ and $42 \mathrm{ml}$ of toluene remained on top. Thus the bead bed of $21.0 \mathrm{ml}$ contained $18 \mathrm{ml}$ of solvent.

\section{Preparation of polymer-supported cinchonidine $\mathbf{1 0}^{\mathbf{2 6}}$}

$1 \%$ Crosslinked polystyrene beads $(80-150 \mu \mathrm{m}$ diameter) were chloromethylated. ${ }^{27}$ The product $(27.0 \mathrm{~g} ; 51.7 \mathrm{mmol}$ of $\mathrm{Cl})$ was treated with thiourea and the intermediate hydrolysed with sodium hydroxide to give beads (28.2 g) containing thiol groups $9 .^{28} \mathrm{By}$ elemental analysis they contained $\mathrm{S}=5.63 \%\left(1.76 \mathrm{mmol} \mathrm{g}^{-1}\right)$ corresponding to a conversion of $96 \%$. The thiol containing beads $(25.0 \mathrm{~g})$ in toluene at $65{ }^{\circ} \mathrm{C}$ were reacted with cinchonidine 6 $(22.0 \mathrm{~g})$ in the presence of AIBN $(3 \times 100 \mathrm{mg})$ to give the PS cinchonidine 10 (35.9 g). Unreacted thiol groups were capped by treating the beads with cyclohex-2-en-1-one in the presence of pyridine. By elemental analysis the final product contained $\mathrm{S}=$ $3.94 \%\left(1.23 \mathrm{mmol} \mathrm{g}^{-1}\right), \mathrm{N}=2.62 \%\left(1.87 \mathrm{mmol} \mathrm{g}^{-1}\right)$ corresponding to loading of cinchonidine residues 10 of $0.94 \mathrm{mmol} \mathrm{g}^{-1}$ and a conversion of $76 \%$.

A portion of the final beads $(3.70 \mathrm{~g})$ was placed in a measuring cylinder $(25 \mathrm{ml})$. The dry beads occupied $6.3 \mathrm{ml}$. Toluene $(15 \mathrm{ml})$ was added and the beads allowed to swell and settle over 2 days. The bed of beads then occupied $10.2 \mathrm{ml}$ and $7.8 \mathrm{ml}$ of toluene remained on top. Thus the bead bed of $10.2 \mathrm{ml}$ contained $7.2 \mathrm{ml}$ of solvent.

\section{Flow apparatus}

The general arrangement of the apparatus used is shown schematically in Fig. 1. The reaction tube was fabricated in house using a commercial Quickfit ${ }^{\mathrm{TM}}$ B14 joint and Pyrex glass tubing. It was $36 \mathrm{~cm}$ long and had an internal diameter of $14 \mathrm{~mm}$. The appropriate amount of PS catalyst was transferred into the tube, toluene was added and the tube sealed with a standard "B14" rubber septum. The tube was set aside for $2 \mathrm{~h}$ to allow the beads to swell. The tube was then immersed $(c a .34 \mathrm{~cm})$ into a water bath whose temperature was controlled by a Techne TU16A Tempunit $^{\mathrm{TM}}$ thermoregulator. Two "inlet" hypodermic needles (19G, 24 in) (supplied by Aldrich) were inserted through the septum so as to reach to the bottom of the tube and one "outlet" needle $(18 \mathrm{G}, 10 \mathrm{in})$ was inserted to just above $(\mathrm{ca} .0 .5 \mathrm{~cm})$ the top of the bead bed. To help the bed settle, toluene was pumped through it for $2 \mathrm{~h}$ using two Watson-Marlow 503U pumps, one equipped with two 501R1 pumpheads (both "inlets" were driven from the same axle) and one equipped with a 303D/A pumphead (for the "outlet"), using Viton ${ }^{\mathrm{TM}}$ (0.8 mm ID) tubing. The "inlet" needles were then attached to reservoirs containing $\mathbf{1}$ in toluene $\left(0.50 \mathrm{mmol} \mathrm{ml}^{-1}\right)$ and compound 2 in toluene $\left(0.53 \mathrm{mml} \mathrm{ml}^{-1}\right)$. The "outlet" needle was passed into a measuring cylinder $(25 \mathrm{ml})$. The pumps were started and fractions $(10 \mathrm{ml})$ collected in the cylinder.

\section{Methyl 1-oxoindan-2-carboxylate (1)}

This compound was synthesised by the method described by House. $^{31}$ 


\section{Reactions (1) using Amberlyst A21 in the flow apparatus}

The following experiments are typical of those summarized in Table 1, entries 1-6. The tube was charged with Amberlyst A21 beads $(15.5 \mathrm{~g})$ and they were allowed to swell in toluene.

Entry 3. The water bath temperature was set to $50{ }^{\circ} \mathrm{C}$. When the temperature was steady, both reactant solutions were pumped through the bed at a rate of $10.5 \mathrm{ml} \mathrm{h}^{-1}$. After $2 \mathrm{~h}$, during which the eluate was simply toluene, fractions $(16 \times 10 \mathrm{ml})$ were collected over the next $14 \mathrm{~h}$. Each fraction was placed in a separating funnel and washed successively with aqueous sodium hydroxide ( $2 \mathrm{M}$; $3 \times 20 \mathrm{ml})$ and water $(2 \times 25 \mathrm{ml})$ and dried. Evaporation of the solvent from a typical fraction $(10 \mathrm{ml})$ gave a clear oil $(501 \mathrm{mg}$; $77 \%$ ) which crystallized with time. It had $v_{\max } 1733$ (ester) and $1711 \mathrm{~cm}^{-1}$ (ketones); $\delta\left(\mathrm{CDCl}_{3}\right.$ solution) 2.13 (3H, s, acetyl), 2.26 ( $2 \mathrm{H}, \mathrm{m}$, side chain methylene), 2.54 ( $2 \mathrm{H}, \mathrm{m}$, side chain methylene), $3.01(1 \mathrm{H}, \mathrm{d}, J 17 \mathrm{~Hz}, 3-\mathrm{H}), 3.68\left(3 \mathrm{H}, \mathrm{s}, \mathrm{OCH}_{3}\right), 3.70(1 \mathrm{H}, \mathrm{d}, J 17 \mathrm{~Hz}$, 3-H) and 7.2-8.0 ppm (4H, m, ArH).

\section{Michael reactions summarized in Table 2}

The following procedures are typical.

Entry 1. Compound 1 (519 mg, $2.73 \mathrm{mmol})$ and methyl vinyl ketone (296 mg, $4.23 \mathrm{mmol}$ ) and the cinchonidine (6) (40 mg, $5 \mathrm{~mol} \%$ ) were dissolved in dry toluene $(10 \mathrm{ml})$ and the mixture was stirred magnetically at $25^{\circ} \mathrm{C}$ under a nitrogen atmosphere for $48 \mathrm{~h}$. The mixture was added to petroleum ether $(30 \mathrm{ml}, \mathrm{bp} 40-$ $\left.60{ }^{\circ} \mathrm{C}\right)$ and filtered. The filtrate was diluted with toluene $(10 \mathrm{ml})$ and washed successively (each $3 \times 20 \mathrm{ml}$ ) with hydrochloric acid (2 M), aqueous sodium hydroxide ( $2 \mathrm{M}$ ) and brine. The organic layer was dried then evaporated to dryness. The oily residue (646 mg, 91\% yield) had FT-IR and ${ }^{1} \mathrm{H}$ NMR spectra identical to those described above. It had $[\alpha]_{578}^{\mathrm{RT}}(c 2.0$, benzene $)-45$. The pure $(S)$-enantiomer is reported to have $[\alpha]_{578}^{\mathrm{RT}}(c 1.9$, benzene $)-77 .{ }^{15}$ Thus the product had an ee of $58 \%$.

Entry 6. Compound 1 (520 mg, $2.73 \mathrm{mmol})$ and methyl vinyl ketone (297 mg, $4.23 \mathrm{mmol})$ and PS cinchonidine 10 (145 mg, $5 \mathrm{~mol} \%$ ) were stirred magnetically in dry toluene $(10 \mathrm{ml})$ at $50{ }^{\circ} \mathrm{C}$ under a nitrogen atmosphere for $3 \mathrm{~h}$. The beads were filtered off and washed thoroughly with toluene. The combined filtrate and washings were then treated as in the previous experiment. The oily residue $(681 \mathrm{mg}, 96 \%)$ was characterized as before. It had $[\alpha]_{578}^{\mathrm{RT}}$ (c 2.0, benzene) -37 , corresponding to an ee of $48 \%$.

\section{Reactions (1) using PS cinchonidine 10 in the flow apparatus}

The following experiment is typical of those summarized in Table 1, entries 7-9. The tube was charged with PS cinchonidine 10 beads $(15.0 \mathrm{~g})$ and they were allowed to swell in toluene.

Entry 8. The water bath temperature was set to $50{ }^{\circ} \mathrm{C}$. When the temperature was steady, both reactants solutions were pumped through the bed each at a rate of $2.5 \mathrm{ml} \mathrm{h}^{-1}$. After $6 \mathrm{~h}$, during which the eluate was simply toluene, fractions $(9 \times 10 \mathrm{ml})$ were collected over the next $18 \mathrm{~h}$. Each fraction was placed in a separating funnel and washed successively with aqueous sodium hydroxide ( $2 \mathrm{M}$; $3 \times 20 \mathrm{ml})$ and water $(2 \times 25 \mathrm{ml})$ and dried. Evaporation of the solvent from a typical fraction $(10 \mathrm{ml})$ gave a clear oil $(631 \mathrm{mg}$, $97 \%$ ) which crystallized with time. The had FT-IR and ${ }^{1} \mathrm{H}$ NMR spectra identical to those described above. It had $[a]_{578}^{R T}(c$ 2.0, benzene) -45 . The pure $(S)$-enantiomer is reported to have $[\alpha]_{578}^{\mathrm{RT}}$ (c 1.9, benzene) $-39.5 .{ }^{14}$ Thus the product had an ee of $51 \%$.

\section{Acknowledgements}

We thank the British Council and the French CNRS for financial support (FB, IC) and Ian Goodbody for carrying out several reactions.

\section{References}

1 See, for example, S. V. Ley, I. R. Baxendale, R. N. Bream, P. S. Jackson, A. G. Leach, D. A. Longbottom, M. Nesi, J. S. Scott, R. I. Storer and S. J. Talyor, J. Chem. Soc., Perkin Trans. 1, 2000, 3815.

2 See, for example, Polymeric Materials in Organic Synthesis and Catalysis, ed. M. R. Buchmeiser, Wiley Interscience, Weinheim, 2003.

3 E. Vickerstaffe, B. H. Warrington and M. Ladlow, J. Comb. Chem., $2005,7,385$.

4 E. Vickerstaffe, B. H. Warrington, M. Ladlow and S. V. Ley, J. Comb. Chem., 2004, 6, 332.

5 A. Kirschning, H. Monenschein and R. Wittenberg, Angew. Chem., Int. Ed., 2001, 40, 650.

6 P. Hodge, Curr. Opin. Chem. Biol., 2003, 1, 2419.

7 G. Jas and A. Kirschning, Chem. Eur. J., 2003, 9, 5708.

8 P. Hodge, Ind. Eng. Chem. Res., 2005, 44, 8542.

9 U. Kunz, H. Schonfeld, W. Solodenko, G. Has and A. Kirschning, Ind. Eng. Chem. Res., 2005, 44, 8548.

10 S. France, D. Bernstein, A. Weatherwax and T. Lectka, Org. Lett., 2005, 7, 3009 .

11 S. Saaby, K. R. Knudsen, M. Ladlow and S. V. Ley, Chem. Commun., 2005, 2909.

12 C. K. Y. Lee, A. B. Holmes, S. V. Ley, I. F. McConvey, B. Al-Duri, G. A. Leeke, R. C. D. Santos and J. P. K. Seville, Chem. Commun., 2005,2175

13 See, for example, (a) C. Simon, J.-F. Peyronel, F. Clerc and J. Rodriguez, Eur. J. Org. Chem., 2002, 3359; (b) K. N. Trivedi, J. Sci. Ind. Res., 1959, 18B, 397.

14 K. Hermann and H. Wynberg, J. Org. Chem., 1979, 44, 2238.

15 H. Wynberg and R. Helder, Tetrahedron Lett., 1975, 4057.

16 P. Hodge, E. Khoshdel and J. Waterhouse, J. Chem. Soc., Perkin Trans. 1, 1983, 2205.

17 E. J. Park, M. H. Kim and D. A. Kim, J. Org. Chem., 2004, 69, 6897.

18 K. Onimura, K. Matsuzaki, Y.-K. Lee, H. Tsutsumi and T. Oishi, Polym. J. (Tokyo), 2004, 36, 190.

19 G. Szollosi and M. Bartok, Chirality, 2001, 13, 614.

20 R. Alvarez, M.-A. Hourdin, C. Cave, J. d'Angelo and P. Chaminade, Tetrahedron Lett., 1999, 40, 7091.

21 A. Sera, K. Takagi, H. Katayama and H. Yamada, J. Org. Chem., 1988, 53, 1157.

22 M. Inagaki, J. Hiratake, Y. Yamamoto and J. Oda, Bull. Chem. Soc. Jpn., 1987, 60, 4121.

23 N. Kobayashi and K. Iwai, J. Am. Chem. Soc., 1978, 100, 7071.

24 See, for example, (a) M. Nakajima, S. Yamamoto, Y. Yamaguchi, S. Nakamura and S. Hashimoto, Tetrahedron, 2003, 59, 7307; (b) T. Suzuki and T. Torii, Tetrahedron: Asymmetry, 2001, 12, 1077, and references cited therein

25 P. Hodge, D. W. L. Sung and P. W. Stratford, J. Chem. Soc., Perkin Trans. 1, 1999, 2335.

26 P. Hodge, E. Khoshdel, J. Waterhouse and J. M. J. Frechet, J. Chem. Soc., Perkin Trans. 1, 1985, 2327.

27 C. R. Harrison, P. Hodge, J. Kemp and G. M. Perry, Makromol. Chem., 1975, 176, 267.

28 J. M. J. Frechet, M. D. deSmet and M. J. Farrall, Polymer, 1979, 20, 675.

29 M. I. Burguete, E. Garcia-Verdugo, M. J. Vicent, S. V. Luis, H. Pennemann, N. Graf von Kerserling and J. Martens, Org. Lett., 2002, 4, 3947.

30 A. M. Hafez, A. E. Taggi, T. Dudding and T. Lectka, J. Am. Chem. Soc., 2001, 123, 10853.

31 H. O. House and C. B. Hudson, J. Org. Chem., 1970, 35, 647. 